must not be lost sight of if the atomic energy industry is to make its mark in the national economy. Mr. Farmer concluded that the safety aim of the atomic energy industry must be for perfection within an economic framework that will encourage the development of the industry.

Each paper presented to the conference was followed by a period of full discussion in which many points of principle and some of detail were discussed. It was agreed that the safety-level established in the atomic energy field compares very favourably with much of established industry, but that a larger experience of radioactive work in industry will be needed before final conclusions can be drawn.

D. R. R. FAIR

\section{RESEARCH ASSOCIATION OF BRITISH RUBBER MANUFACTURERS}

\section{OPENING OF NEW LABORATORIES NEAR SHREWSBURY}

$\mathrm{O}^{\mathrm{s}}$ November 23 H.R.H. the Duke of Edinburgh officially opened the new laboratories and headquarters at Shawbury, near Shrewsbury, of the Research Association of British Rubber Manufacturers. Some three hundred persons were present, drawn from all sections of the rubber and allied industries, together with representatives of government departments and other organizations connected with the rubber industry, and after the opening they were able to visit the premises and inspect the displays showing various aspects of the Association's work. In his speech to the company the Duke referred to the obligations of industry towards cooperative research and its results, and put in a strong plea for yet more generous financial support by industry of the Association's work. He also stressed very much the problem of getting a research association's results applied in industry - "probably the most complicated and elusive problem confronting the industry to-day".

The ceremony formed a fitting and stimulating climax to the efforts that have been made during the past years to provide the Association with premises adequate for its growing needs. Founded in 1919, the Research Association of British Rubber and Tyre Manufacturers (as it was first called) began work in two rooms in University College, London, and then in 1922 premises were acquired in Lansdowne Road, Croydon. For many years these met the Association's needs ; but the very success of its work, and especially the demands made on it during the Second World War, led to an expansion that seriously overtaxed the available space. By 1948 it became clear that the only solution was to find entirely new premises, and bearing in mind that the 'centre of gravity' of the rubber industry lies in the Midlands rather than the London area, the Council of the Association decided, after exhaustive inquiries and searches, to acquire premises already existing at Shawbury. These were purchased in January 1952, and since then the task of adapting them has proceeded steadily. Now that task is complete and the premises have been officially opened, the industry possesses a research station of excellent design, attractive in external appearance and interior finish, and fully equipped for the important work that lies before it.

The new premises (Fig. 1) are near the village of Shawbury, $6 \frac{1}{2}$ miles north-east of Shrewsbury on the Market Drayton Road ( $A$ 53). Erected in 1938 by Shropshire County Council, they have a floor area of some $15,000 \mathrm{sq}$. ft. and stand on a level site of about $6 \frac{1}{2}$ acres. The whole building is on one floor, except for two flats over the front portion. Although built for a different purpose, the lay-out has proved surprisingly convenient for the laboratories, library, workshops and offices of the Research Association.

The laboratories proper are grouped into three categories: chemistry, physics and technology. The chemical laboratories are in two groups. In the first, the main laboratory is for analytical work, including the testing of raw materials, analysis of vulcanized rubbers, identification and estimation of synthetics, and so on, and has for this purpose many pieces of specialized apparatus. The equipment includes also a micro-balance, used in developing micro-chemical techniques applicable to rubbers and other polymers, a Spekker absorptiometer for colorimetric analyses, and an infra-red spectrometer which has been devoted particularly to the identification of organic accelerators and antioxidants in vulcanized rubbers. Other laboratories are fitted up for studies on adsorption of simple hydrocarbons on carbon black and other powders, as part of the research on the mechanism of filler reinforcement. The second group includes the main chemical research laboratory, at present devoted largely to studies on copper (and other heavy-metal) catalysis of oxidation and the development of improved sequestering agents for combating the effect of copper in promoting oxidative deterioration (ageing) of rubber.

The physics laboratories comprise two large adjacent rooms, one of which is devoted mainly to electrical measurements and has a full range of equipment for studies of volume and surface resist-

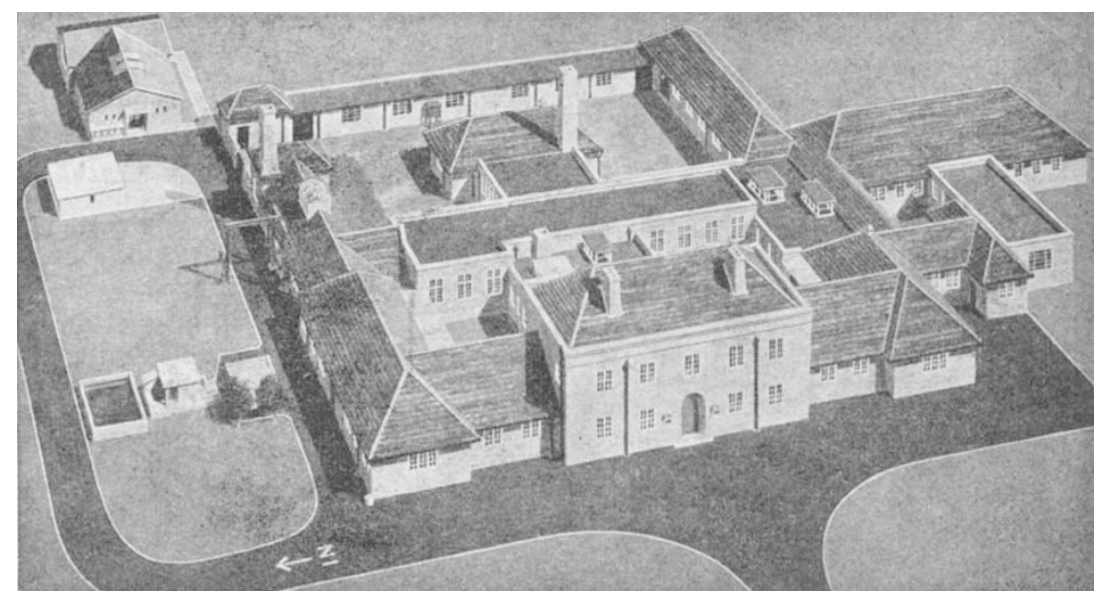

Fig. 1. Aerial view of new Laboratories of the Research Association of British Rubber Manufacturers 
ivity, permittivity and power factor, as well as special apparatus for testing the electrical characteristics of 'anti-static' rubber, a subject to which the Association has made important contributions. Highvoltage equipment is housed in the adjoining laboratory, which also deals with studies on plasticity, using in particular the Association's 'shearing-cone plastimeter' and various other types (Fig. 2). In this room also is installed the new sinusoidal-strain dynamic testing machine constructed to designs worked out by the Association, and which will enable more complete studies of the dynamic behaviour of vulcanized rubber to be undertaken than have hitherto been possible.

The technological laboratories include the mill room, equipped with up-to-date experimental mixing plant (both open-roll and internal types) and vulcanizing equipment (platen presses and open-steam pan); and the mechanical testing laboratory, which possesses a full range of instruments for examining the physical characteristics of vulcanized rubbers-strength, extensibility, 'set' or residual deformation, hardness, resilience, resistance to tearing and to abrasion, behaviour at low temperatures, etc. (Fig. 3). These instruments, particularly those for testing hardness, include several designed by the Association or by member firms on the basis of studies by the Association. Auxiliary laboratories contain equipment for testing the resistance of rubber to repeated flexing and to the deteriorating actions of heat, oxidation, light and atmospheric ozone. This technological equipment enables the research staff to prepare experimental rubber samples under carefully controlled conditions and to assess their properties and likely behaviour during use.

In addition to these various laboratories, the premises include the library and information section, or Intelligence Division, as it is called. This contains what is believed to be the world's largest library on rubber and cognate subjects such as rubber-like

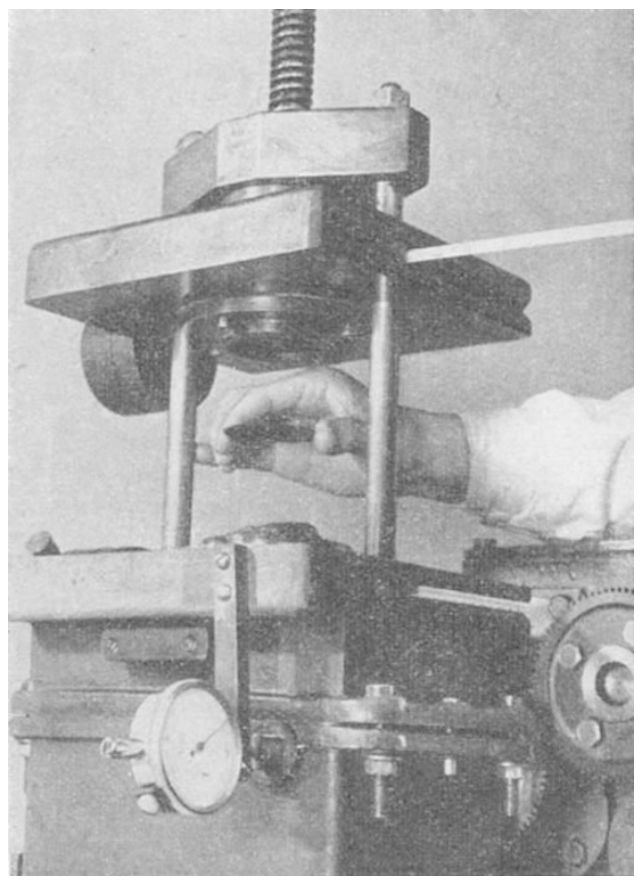

Fig. 2. Shearing-cone plastimeter for rubber

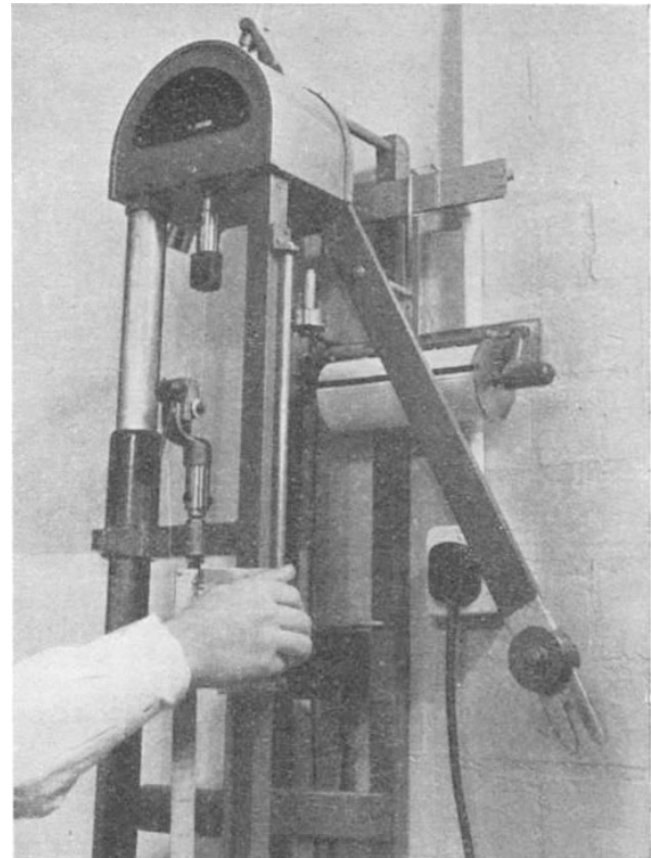

Fig. 3. Hounsfield tensile test machine, a recent British development

plastics, together with card indexes, now totalling some 750,000 cards, on which scientific, technical and commercial information on rubber is arranged in classified order for easy reference in answering inquiries and preparing literature surveys. Offices for typing and duplicating work, a photographic dark-room, an engineering workshop, and a spacious canteen complete the layout of a research station of which the rubber industry may well feel proud.

\section{TREATMENT AND DISPOSAL OF SEWAGE SLUDGE}

CINCE methods of treating water-borne sewage $D$ were first adopted in Britain, it has seemed obvious to many people that it should be possible to utilize profitably the plant nutrients which the liquid contains. That it is at least difficult to do this, and at the same time to dispose of the material without causing a nuisance or endangering public health, became clear during the second half of the past century when most of the sewage in inland districts was disposed of by irrigation on 'sewage farms'. For various reasons this method fell into disreputelarge areas of land were needed; land is usually expensive near towns, where most of the sewage is produced; the soil must be porous to permit irrigation at a reasonable rate; the sewage is produced continuously, but the farmer prefers to take it for irrigation only intermittently. Most sewage farms have now been replaced by modern, compact treatment plants which, at a remarkably low cost, are capable of converting sewage--often containing a large proportion of industrial wastes - into effluents which can be discharged to the small streams of Britain without serious risk to public health. The possibility of maintaining this position, but at the same time recovering further useful materials from 